\title{
Accounting for Management Control in Large Libyan Companies
}

\author{
By Adel R. Haedr ${ }^{*}$ \\ Messaoud Mehafdit
}

\begin{abstract}
The study gives an account of management control practices in Libya during a period of relative political and economic stability that preceded the 2011 war and regime change. Using a two-level contingency model and survey data, stepped mediation regression first ascertains contingency relationships between organisational variables and management control system (MCS) effectiveness. We also explicitly focus on the mediating role of management accounting information (MAI) in MCS effectiveness. We find that centralisation, formalisation, environmental uncertainty and competitive strategy significantly influence MCS effectiveness. Full mediation is observed in relation to centralisation, whereas partial mediation is detected for formalisation, environmental uncertainty, and competitive strategy. Manufacturing process complexity is not present in first level relationships and further tests only yielded an indirect MAI effect, not mediation in this case. The full vs. partial mediation distinction is not evident in most previous MCS interaction research, nor is the isolation of the indirect effect, and future research needs to explore this with larger samples. This is possibly the first study to develop and apply a multi-level contingency model that explicitly focuses on the mediating role of MAI to empirically examine MCS effectiveness and contributes to the nascent literature on management accounting in emerging economies.
\end{abstract}

Keywords: Management control, accounting information, mediation

\section{Introduction}

The purpose of this paper is to examine the interplay between organisational variables and management control systems (MCS) in manufacturing companies in Libya and the role of management accounting information (MAI) in mediating MCS effectiveness. The management control literature mainly consists of studies conducted in developed countries. Little is known about management control systems in developing countries, particularly in Africa. Attempts to alleviate this paucity (e.g. Bampoky and Meyssonnier, 2012) are limited in scope, thus unable to unravel the complex nature of MCS. This study contributes focused research to improve understanding of MCS contingency relationships by examining MCS in Libyan companies and the role of management accounting information in facilitating effective MCS. In mature market economies MCS are perceived essential tools to cope with change (Anthony and Govindarajan, 2007). MCS are not less important in emerging economies (Hopper et al., 2009; Auzair, 2011; Albu and Albu, 2012)

\footnotetext{
${ }^{*}$ Faculty of Economics \& Commerce, Al Asmarya University, Zliten, Libya.

${ }^{\dagger}$ Business School, University of Huddersfield, West Yorkshire, UK.
} 
but whether they are effective management tools is an empirical question that this study contributes to answering.

Libya is an example of an emerging economy that has been experiencing transformational change, making it an ideal place to study management control practice. Being the holder to Africa's largest crude oil reserves, Libya has been a top investment destination for international oil companies (AfBD, 2014; KPMG, 2014) and an active participant in global value chains (Abughalia and Abusalem, 2013; Nicita et al., 2013). Market reforms and a better investment climate were put in motion in the mid-1980s through privatisation and a gradual move away from socialist dirigisme. This study is based on the experience of managers whose companies have been central to the economic transition programme. Key results indicate that organisational variables vary in their influence on MCS effectiveness to ensure successful implementation of strategies, with a clear importance attached to formalisation processes in an economy undergoing transformational change. We also find that MAI is a strong conduit for this influence, particularly with respect to centralisation and formalisation, which are key levers of management control in these environments.

The remainder of this paper is organised as follows. First, relevant literature is summarised, highlighting the foci of previous studies as well as their inconsistencies with regard to their treatment of MAS/MCS interactions. Second, the present study's theoretical model, research hypotheses and data collection approach are presented. Third, statistical tools used are then explained, followed by the study findings and their implications for both MCS research and practice.

\section{Literature Review and Theoretical Model}

A hurdle that is encountered in designing this type of study is the absence of guidance from the largely amorphous literature on how to undertake much needed research on MCS/MAI interactions in non-traditional settings without risking a disproportionate research effort on a complex and data-deficient topic. Contingent relationships in MCS research have often been conceptually and operationally misspecified, prompting calls for a more inclusive research approach (e.g. Chenhall, 2007; Anthony and Govindarajan, 2007; Strauß and Zecher, 2013; Silva-Domingo, 2015) that also pays close attention to MCS practices in developing countries (e.g. Waweru et al., 2004; Hopper et al., 2009). MCS have been examined from both a financial control perspective (e.g. Naranjo-Gil and Hartmann, 2006) and a non-financial control perspective (e.g. Hoque, 2004), however accounting-based controls have largely dominated the research effort. Heeding the calls for more adequate theoretical constructs, we developed an encompassing contingency model of the potential influence of organisational factors, in particular centralisation, formalisation, environmental uncertainty, manufacturing complexity, and competitive strategy, on the effective design and use of MCS in large companies in Libya, taking into 
account the possible mediating role of MAI. Previous studies that tried to capture the role of MAI (e.g Choe, 1998; Soobaroyen and Bhagtaraj, 2008) used Chenhall and Morris's (1986) characterisation of MAI (e.g. usefulness, availability, use, importance) but with a focus limited to few organisational variables. Moreover, the mediating role of all four MAI characteristics on the relationship between organisational variables and the outcome variable has been largely overlooked. Critical to this study is therefore the careful specification of its two-level contingency-based theoretical model.

Of particular methodological significance is the problem of model misspecification of third variables in causal models as some MCS/MAI studies that used the mediation model incorrectly tried to look for consistency or contrast of their findings with other studies that tested for moderation (e.g. Chong and Chong, 1997; Chong and Eggleton, 2003). The moderation and mediation forms of fit have fundamentally different theoretical meanings; consequently results based on one model cannot be validated with results obtained from the other (Baron and Kenny, 1986). This confusion is exacerbated further as some studies claimed to report the mediating role of a third variable, whereas in fact their findings only showed the indirect effect of the independent variable through that third variable (e.g. Teerooven and Bhagtaraj, 2008). We overcome these inconsistencies by fully examining the intervening role of MAI on the relationship between organisational variables and MCS effectiveness, and distinguishing mediating effects from other forms of interaction. Figures 1 and 2 below depict the study's two-level contingency model.

Figure 1. First Level MCS Contingency Relationships

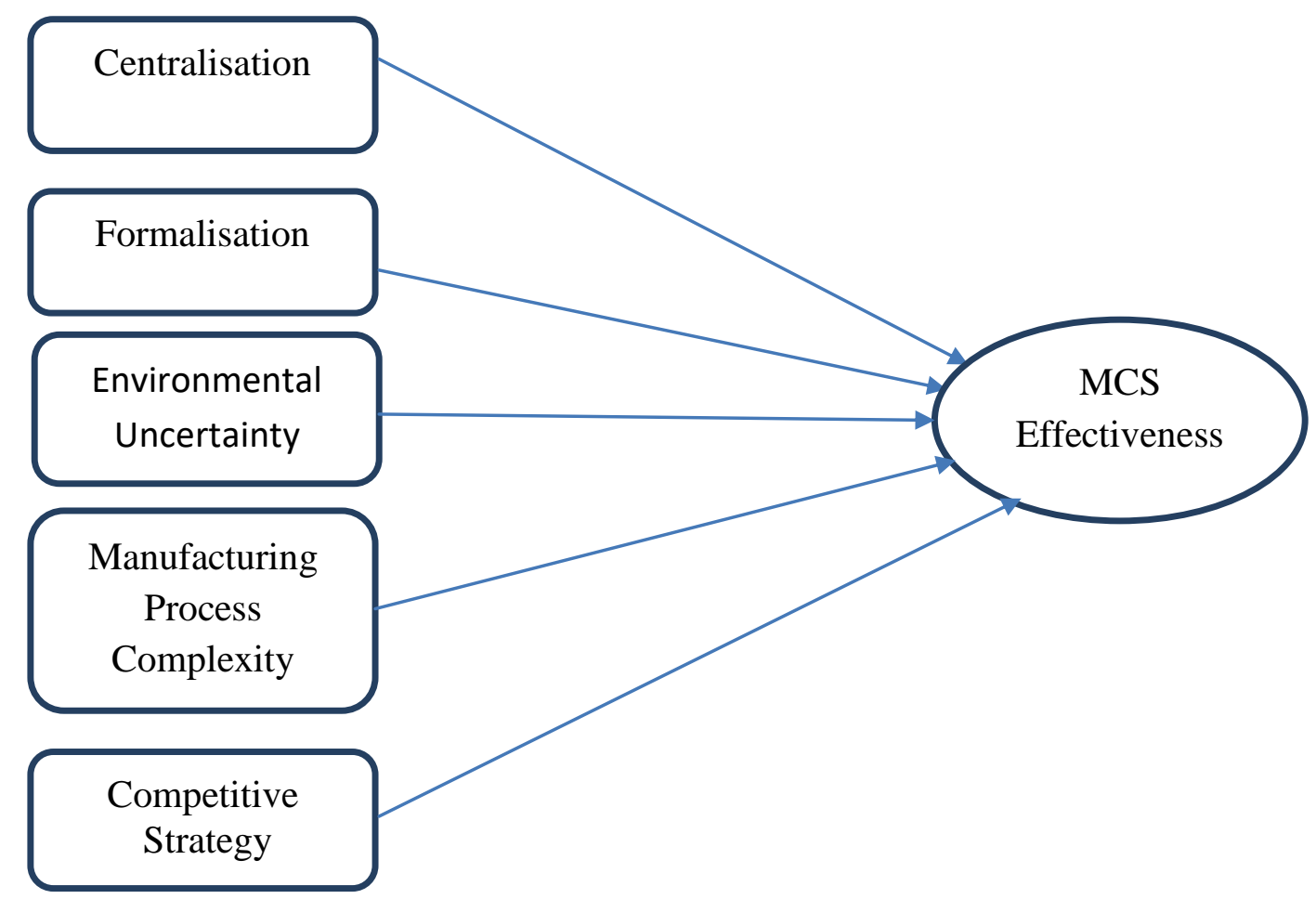


At the first level (see Figure 1, and path $c$ in Figure 2 Panel A), MCS are examined in terms of aspects of organisational structure, environmental uncertainty, manufacturing process complexity, and organisational strategy. At a second level, the contingency model attempts to capture the mediating role of MAI to offer a deeper understanding of the first level contingency relationships (see Figure 2 Panel B paths $a, b$ and $\dot{c}$ ). The value of $c$ is expressed as the difference between the initial total relationship if it exists less the mediated part of this relationship, i.e. $\dot{c}=c-a b$. Path $\dot{c}$ represents the non-mediated part of the contingent relationship, so if the relationship is fully mediated, $c$ will be insignificant as it will be closer to zero than $c$. If however $c$ does not exist, then $a b$ only indicates an indirect effect, not a mediated relationship (see path $a, b$ in Figure 2 Panel $\mathrm{C}$ ). The hypotheses formulated for both levels of contingency relationships are presented next.

Figure 2. Second Level MCS Contingency Relationships (Mediation) Panel A: Initial Total Effect

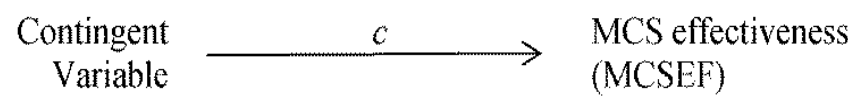

Panel B: Mediated Initial Relationship

MAI

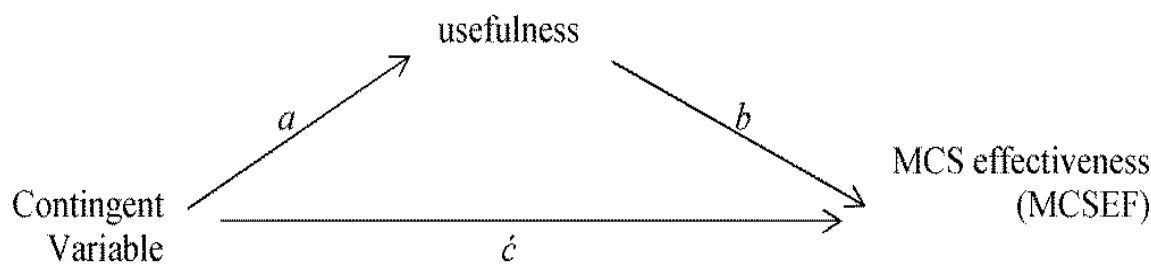

Panel C: Indirect Relationship

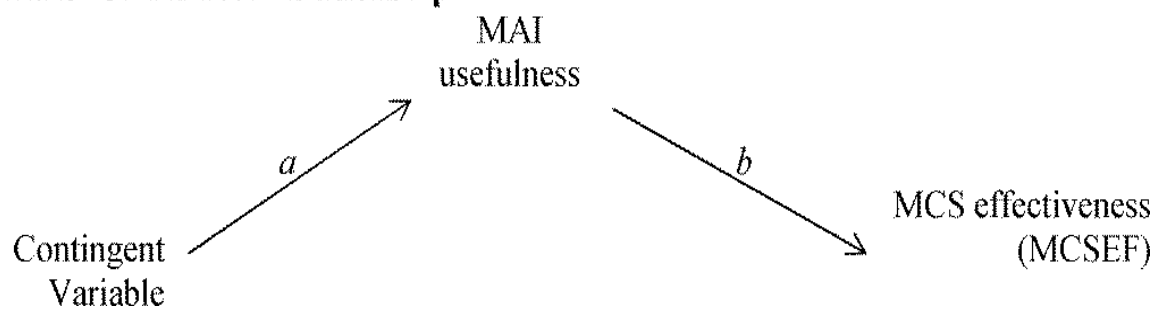

Panel A: Initial non-mediated effect of organisational variables on MCS effectiveness

Panel B: Mediated initial contingency relationships through MAI usefulness

Panel C: Absence of mediation but presence of indirect relationship between contingent variables and MCS effectiveness 


\section{Research Hypotheses}

\section{1) First Level Contingency Relationships: Organisational Variables and MCS Effectiveness}

\section{(De)centralisation}

Centralisation is concerned with the degree decision making autonomy. Research studies have consistently reported a positive relationship between the level of centralisation and performance. Bruns and Waterhouse (1975) found that managers of decentralised firms were more involved in budget planning and satisfied with budget-related behaviour. Merchant (1981) reported that managers in large decentralised companies tend to participate more in preparing budgets on a formal level and attached more emphasis to meet their targets, which resulted in a good organisational performance. King et al. (2010) also reported positive attitudes to budgeting in decentralised companies, whereas the interaction between decentralisation settings and MAI/MCS information with regard to organisational performance is established in a number of studies (e.g. Gul and Chia, 1994; Chia, 1995; Soobaroyen and Bhagtaraj, 2008). Chang et al. (2003) found that companies who authorised and delegated decision making to the lower levels of the firm's hierarchy satisfied MAI users, and this reflected on the effectiveness of MAS. These findings from previous research indicate that, in situations where levels of centralisation are low, this is expected to have a positive influence on MCS effectiveness and vice versa, in the presence/absence of relevant information. We therefore hypothesise that

\section{Hypothesis 1: Centralisation, as an aspect of organisational structure, positively influences the effectiveness of an MCS.}

\section{Formalisation}

Organisational formalisation specifies the extent to which rules, procedures, instructions and communications are written to prescribe behaviour (e.g. Hage and Aiken, 1967, 1969). Tight control, where rules and control procedures are embedded within organisational routines and systems, is associated with highly formalised organisations. Therefore, regular monitoring of organisational actions is required to achieve a successful implementation to the desired goals (Nicolaou, 2000). As evidenced by the few studies that examined this variable, the degree of formalisation influences the strategic decision making process (e.g. Fredrickson, 1986), organisational coordination and control requirements (e.g. Nicolaou, 2000) and the effective design of MAS (e.g. Gerdin, 2005). Hence our hypothesis that

Hypothesis 2: Formalisation, as an aspect of organisational structure, positively influences the effectiveness of an MCS. 


\section{Environmental Uncertainty}

A powerful contextual variable at the foundation of contingency-based research is a company's external environment, and uncertainty is the most widely addressed aspect of this environment (Chenhall, 2003, 2007). Environmental uncertainty has been empirically linked in MCS research not only to the usefulness of MAI (e.g. Chenhall and Morris, 1986; Baines and Langfield-Smith, 2003) but also to its scope and timeliness because under high environmental uncertainty situations decision makers demand more timely information to decrease the level of ambiguity and take the desired actions in order to accomplish their organisation's targets (e.g. Chenhall and Morris, 1986; Fisher, 1996). Given the actions taken by the Libyan government since the late 1980s and more so recently to gradually liberate the market, companies in Libya are expected to face more uncertain situations. The expected effect of this on the effectiveness of MCS is hypothesised as follows:

\section{Hypothesis 3: Environmental uncertainty significantly influences the effectiveness of an MCS.}

\section{Manufacturing Process Complexity}

Manufacturing process complexity refers to the diversity of product lines, processes and volumes (Abdel-Kader and Luther, 2008). Companies may introduce new technologies in order to improve their competitive advantage and this introduction requires them to change the manufacturing process and adapt their MCS accordingly (Bruggemann and Slagmulder, 1995). On the other hand, companies that produce standardised, undifferentiated products tend to employ mass production and process technologies. These circumstances require standardised, administrative MCS such as traditional formal financial controls (Chenhall, 2007). With the exception of Abdel-Kader and Luther (2008), studies tends to show positive relationships between manufacturing process complexity, the adoption of sophisticated MAS and improved organisational performance (Krumwiede, 1998; Baines and Langfield-Smith, 2003). Other studies linked changes in this contingent variable to changes in other related circumstances. For instance, Bruggemann and Slagmulder (1995) argued that companies could introduce new technologies in order to improve their competitive advantage, creating the need for synchronous change in manufacturing process and MAS/MCS to align information needs with technological change. Similarly, Baines and Langfield-Smith (2003) found that the change in the competitive environment was simultaneously accompanied by changes in strategic priorities, organisational design, manufacturing technology, and more reliance on non-financial MAI. These changes resulted in enhancing organisational performance. Therefore, consistent with the above discussion, we theorise that

Hypothesis 4: The level of manufacturing process complexity significantly influences the effectiveness of an MCS. 


\section{Competitive Strategy}

The MCS and strategy literature offers various typologies to describe the generic competitive strategies of companies (e.g. Miles and Snow, 1978; Porter, 1980) and the important and strong relationship between competitive strategy and MCS has been highlighted in many earlier and more recent studies (e.g. Langfield-Smith, 1997; Chenhall, 2003; Langfield-Smith, 2007). This relationship is based on the notion that when pursing competitive advantage, many companies are likely to implement administrative functions (e.g. MCS) that support their particular strategic priorities (Chenhall and Langfield-Smith, 1998). For instance, low emphasis on meeting budgets is found in high performing companies following differentiation priorities (e.g. Govindarajan, 1988), and that the interactive use of budgets positively influences the relationship between strategic priorities and organisational performance (e.g. Jermias and Gani, 2004) concluded that organisational performance is improved as a result of the match between the organisational factors regardless of the adopted strategic priorities, whereas Hoque (2004) highlighted the critical role of non-financial indicators in this respect. It is therefore hypothesised that

Hypothesis 5: Competitive strategy significantly influences the effectiveness of an MCS.

\section{2) Second Level Contingency Relationships: The Mediating Role of MAI}

The mediating role of MAI has received reasonable attention in previous studies. For instance, Mia (1993) reported the mediating role of scope of MAI on the relationship between perceived environmental uncertainty and managerial performance and job satisfaction. Similarly, Mia and Clarke (1999) found that an increase in the market competition increased the use of MAI which in turn led to performance improvement. Chong and Chong (1997) found that competitive strategy and environmental uncertainty were important antecedents to the use of MAI and this in turn had a positive influence on performance. With respect to the centralisation variable, Soobaroyen and Bhagtaraj (2008) found a positive indirect association between decentralisation and managerial performance. This association only appears via the availability of broad scope MAI. In relation to the manufacturing process complexity, Mia and Winata (2008) reported that the influence of advanced production methods (e.g. JIT) on the use of information and communication technology appears only indirect through scope of MAI. We therefore conclude that MAI can be safely examined as a mediator variable in the workings of MCS; hence the following hypotheses for our mediational model in relation to the previously defined first level contingency variables (i.e. centralisation, formalisation, environmental uncertainty, competitive strategy, manufacturing process complexity): 
Hypothesis 6: Management accounting information mediates the effect of first level contingent factors on MCS effectiveness.

\section{Method}

\section{Data and Sample}

The empirical analysis in this study aims primarily at understanding ' what $i s$, hence the cross-sectional survey approach to primary data collection. It was planned to collect data from all 60 large manufacturing companies in three stages (initial survey, interviews and follow-ups for a longitudinal approach). However, once the initial questionnaire survey was completed, political unrest in 2011 and the subsequent factional war prevented any additional data collection. This paper uses the primary data from the initial survey to report management control practices in a period of relative economic stability underlined by on-going market reforms. The questionnaire consisted of a mix of mostly closed questions (category, list, quantity questions and rating questions) with 5-point Likert scales used for the rating question type. Before piloting it to five companies, the final version of the questionnaire was translated from English into Arabic and tested for accuracy and clarity of content through independent evaluation by three bilingual academics at Misrata University in Libya. Table 1 summarises the respondents per industrial sector.

Table 1. Profile of Participating Companies and Respondents

\begin{tabular}{llcc}
\hline \multirow{3}{*}{ Manufacturing sector } & Food making & Number & Percentage \\
\cline { 2 - 3 } & Chemical & 21 & 38.9 \\
& Engineering and electrical & 5 & 9.3 \\
& Metal & 2 & 3.7 \\
& Cement and building & 5 & 9.3 \\
& materials & 11 & 20.4 \\
& Oil and gas & 3 & 5.6 \\
& Other & 7 & 13 \\
Ownership type & State-owned & $\mathbf{5 4}$ & $\mathbf{1 0 0 . 0}$ \\
& Private-owned & 28 & 51.8 \\
& Joint venture & 16 & 29.6 \\
Respondent's & Total & 10 & 18.6 \\
position & Chief of Management Board & 54 & 100.0 \\
& Member of Management & 7 & 14.8 \\
& Board & & \\
& Chief Executive Officer & 6 & 13.0 \\
& Finance Director & 23 & 11.1 \\
& Management Accountant & 7 & 42.6 \\
& Other & 3 & 13.0 \\
& & $\mathbf{5 4}$ & $\mathbf{1 0 0 . 0}$ \\
\hline
\end{tabular}




\section{Variables Measurement}

Table 2 shows variables conceptualisation and Table 3 contains descriptive statistics and reliability tests. All Cronbach alpha results of the questionnaire's multipoint-scaled items exceed the recommended 0.6 reliability threshold (e.g. Hair et al., 2016), indicating overall internal consistency of the research constructs. A company's MCS was recognised as more bureaucratic if the overall mean value of answers to 15 question items given was $\geq 3.00$. Managers in this study seem to prefer bureaucratic MCS (overall mean score = 3.49) to motivate, monitor, control and direct activities and are driven by formal control, e.g. budgeting systems $($ mean $=3.65)$, tight control $($ mean $=$ 3.51 ), as well as impersonal control (mean $=3.52$ ).

Centralisation. This variable was measured using the instruments developed by Hage and Aiken (1967) and Pugh et al. (1968) and commonly used in previous studies (Merchant, 1981; Chenhall and Morris, 1986). The respondents were asked to indicate, on a five point scale $(1=$ never delegated; 5 = always delegated), the extent to which decisions were delegated to middle/operational managers by top management in their companies.

Formalisation. The construct used to measure this variable was adapted from Hage and Aiken (1967). The respondents were asked to indicate to what extent rules, routines and job descriptions guide managers in their companies, on a five point scale ( $1=$ not at all; $5=$ to a considerable extent). This instrument was used in previous research (e.g. Nicolaou, 2000).

Environmental uncertainty. To ascertain environmental uncertainty, managers were asked to indicate the degree of predictability of a number of aspects, on a five point scale ( $1=$ not at all; $5=$ to a considerable extent). This instrument was developed by Govindarajan (1984) and commonly adopted in previous studies (Chenhall and Morris, 1986; Gul and Chia, 1994; Fisher, 1996; Abdel-Kader and Luther, 2008).

Manufacturing process complexity. Using five points scale ( $1=$ not at all; 5 $=$ to a considerable extent), managers were asked to indicate the product lines diversity in their companies. This question was adapted from Krumwiede (1998).

Competitive strategy. Chenhall and Langfield-Smith (1998) widely used rating scale was used here and the respondents were asked to indicate the degree of emphasis they attached to 13 activities in relation to strategic priorities. 
Table 2. Variables Conceptualisation

\begin{tabular}{|c|c|c|}
\hline Variables & Type & Definition \\
\hline $\begin{array}{l}\text { MCS effectiveness } \\
\text { (MCSEF) }\end{array}$ & Dependent & $\begin{array}{l}\text { Adequacy of MCS that matches } \\
\text { organisation's settings and requirements to } \\
\text { ensure successful implementation of } \\
\text { strategies. }\end{array}$ \\
\hline $\begin{array}{l}\text { MAI usefulness } \\
\text { (MAIUSF) }\end{array}$ & $\begin{array}{l}\text { Mediator } \\
\text { (dependent } \\
\& \\
\text { independent) }\end{array}$ & $\begin{array}{l}\text { Relevant information that facilitates effective } \\
\text { MCS in relation to strategies and performance }\end{array}$ \\
\hline $\begin{array}{l}\text { Centralisation } \\
\text { (CENT) }\end{array}$ & Independent & $\begin{array}{l}\text { The degree of (not) delegating authority to } \\
\text { make decisions }\end{array}$ \\
\hline $\begin{array}{l}\text { Formalisation } \\
\text { (FORM) }\end{array}$ & Independent & $\begin{array}{l}\text { The extent to which rules, procedures, } \\
\text { instructions and communications are written } \\
\text { to prescribe behaviour. }\end{array}$ \\
\hline $\begin{array}{l}\text { Environmental } \\
\text { uncertainty (ENUC) }\end{array}$ & Independent & $\begin{array}{l}\text { Lack of information on the environmental } \\
\text { factors, inability to assign probabilities on } \\
\text { how the environment will affect success or } \\
\text { failure. }\end{array}$ \\
\hline $\begin{array}{l}\text { Competitive strategy } \\
\text { (CMSTG) }\end{array}$ & Independent & $\begin{array}{l}\text { The way that organisations try to achieve a } \\
\text { competitive advantage in relation to their } \\
\text { main competitors (Porter's typology of cost } \\
\text { leadership and differentiation). }\end{array}$ \\
\hline $\begin{array}{l}\text { Manufacturing process } \\
\text { complexity (MAPCX) }\end{array}$ & Independent & $\begin{array}{l}\text { Diversity of product lines, processes and } \\
\text { volumes. }\end{array}$ \\
\hline
\end{tabular}

MAI usefulness. Previous attempts at examining the role of MAI in an organisational context often excluded relevant contingent variables, resulting in a fragmented view (Fisher, 1995) of what in essence is a complex phenomenon. The measurement of this variable was based on the instrument developed by Chenhall and Morris (1986) and the respondents were asked to indicate on a five point scale the importance $(1=$ not important; $5=$ very important) and availability ( $1=$ not available; $5=$ always available) of MAI. The scores on the 20 items obtained from both scales were used to calculate and create a composite variable, namely usefulness of MAI (i.e. importance $\times$ availability), which is used for further analysis as the mediator variable. This approach has been used in previous accounting research (e.g. Abdel-Kader and Luther, 2008) and the logic behind creating this new variable is that if information is important and available, it would be perceived useful by managers for decision making and solving problems, whereas if it is important and not available or not important but available, it is considered not useful. 
Table 3. Descriptive Statistics and Reliability Tests

\begin{tabular}{lcccccc}
\hline Variables & Mean & SD & Min & Max & Items & Alpha \\
\hline MCS effectiveness (MCSEFC) & 4.01 & .74 & 1.50 & 5.00 & 3 & .75 \\
MAI usefulness (MAIUSF) & 14.41 & 4.87 & 3.40 & 25.00 & 20 & .95 \\
Centralisation (CENT) & 2.87 & 1.04 & 1.00 & 4.88 & 8 & .90 \\
Formalisation (FORM) & 3.78 & .84 & 1.00 & 5.00 & 4 & .79 \\
Environmental uncertainty (ENUC) & 3.51 & .83 & 1.67 & 5.00 & 9 & .90 \\
Competitive strategy (CMSTG) & 3.77 & .76 & 2.00 & 4.92 & 13 & .92 \\
Manufacturing process complexity & 3.29 & .77 & 1.20 & 4.60 & 5 & .64 \\
(MAPCX) & & & & & \\
\hline
\end{tabular}

MCS effectiveness. Contingency theory studies have recognised effectiveness as an important dependent variable in matching MCS and organisational variables (e.g. Langfield-Smith, 1997; Nicolaou, 2003; Jermias and Gani, 2004; Adebayo and Annukka, 2009). Given the adopted definition of MCS for the current study and the role of MCS to support competitive strategy (e.g. Govindarajan and Fisher, 1990), the effectiveness of an organisation's MCS reflects how well these systems are designed to support the requirements related to strategy formulation and implementation. As a direct question on whether an MCS was effective was potentially very sensitive and thus would produce nil or biased responses, it was instead decided to capture data via a set of seven determinants of MCS effective design. These were drawn from the literature (e.g. Chenhall, 2003; Anthony and Govindarajan, 2007; LangfieldSmith, 2007) and respondents were asked to rate each one on a five point scale ( $1=$ not at all, $5=$ to a considerable extent). The results of principal component analysis show that four items relate to the design and implementation of an MCS (first factor in Table 4), and three items are relevant to MCS effectiveness (second factor) which is the focus of this study. MCS effectiveness is the dependent variable when testing the research hypotheses.

Table 4. Principal Component Analysis Results

\begin{tabular}{|c|c|c|}
\hline \multirow{2}{*}{ Items } & \multicolumn{2}{|c|}{ Component } \\
\hline & 1 & 2 \\
\hline The incentive schemes play a key role in the success of the MCS & .834 & \\
\hline $\begin{array}{l}\text { The success of the MCS depends on senior management } \\
\text { commitment }\end{array}$ & .751 & \\
\hline $\begin{array}{l}\text { The MCS is designed to be adaptable to changing } \\
\text { circumstances }\end{array}$ & .696 & \\
\hline The success of the MCS depends on the quality of its design & .656 & \\
\hline The current MCS is sufficiently adequate for the company & & .914 \\
\hline $\begin{array}{l}\text { The MCS exists mainly to ensure successful implementation of } \\
\text { strategy }\end{array}$ & & .879 \\
\hline Management accounting information is vital for the MCS & & .515 \\
\hline $\begin{array}{l}\text { Kaiser-Meyer-Olkin Measure of Sampling Adequacy (KMO) } \\
.727 ; p<.001\end{array}$ & & \\
\hline Initial Eigenvalues & & \\
\hline Total & 3.320 & 1.245 \\
\hline$\%$ of Variance & 47.426 & 17.787 \\
\hline Cumulative \% & 47.426 & 65.213 \\
\hline
\end{tabular}




\section{Statistical Methods}

In addition to descriptive statistics, regression analysis is applied, in accordance with the Baron and Kenny (1986)'s stepped approach, to first level contingency relationships to examine the possible influence of the investigated organisational variables on the effectiveness of MCS. For second level contingency relationships, the Preacher and Hayes (2004) macro was loaded onto SPSS to deal with the hypothesised mediational role of MAI in the first level contingency relationships. Mediation may be full, partial or non-existent and the Preacher and Hayes' macro is the most advanced tool that can be used for dealing with mediation scenarios using small data samples and, to the best of our knowledge, it has not been used by previous relevant studies. For instance, Hsu and Wang (2012) relied on hierarchical regression, which is a less robust technique, in their recent study of the relationship between intellectual capital and performance. While hierarchical regression only performs one type of test, the Preacher and Hayes macro performs three simultaneous tests (regression, Sobel, and bootstrapping) all of which are necessary for properly capturing the effect of a mediating variable.

Specifically, the first test of the macro's outcome is known as the Baron and Kenny (1986) method (i.e. causal steps approach) which produces four regression models. Model one examines the total (or initial) effect of an independent variable on the dependent variable (path $c$ in figure 2, Panel A). If $c$ is established, the next step is to check for mediation through models 2, 3 and 4. If, however, $c$ does not exist, we can only talk about an indirect effect not a mediated relationship (see path $a, b$ in Figure 2 Panel C). The second model is for regressing the mediator on the independent variable (path $a$ in Figure 2, Panel B) whereas the third model examines the effect of the mediator on the dependent variable with the presence of and controlling for the effect of the independent variable (path $b$ in Figure 2, Panel B). The fourth model is for examining whether the total relationship continues to exist after the mediator was introduced and controlled for (path $c$ in Figure 2, Panel B). As explained earlier, path $c$ represents the non-mediated part of the total relationship, so if there is full mediation $\dot{c}$ will be insignificant. Therefore, a significant $\dot{c}$ indicates partial mediation.

The second test, named after Sobel (1982), treats and calculates path ' $a$ ' and ' $b$ ' as one model rather than two models as in the Baron and Kenny method and, therefore, returns one value for the $a b$ path. The Sobel test is frequently used as a supplement to the causal steps approach rather than instead of it (Hayes, 2009). However it is possible for the Sobel test to contradict with the causal steps results and suggest no indirect effect. This occurs when Baron and Kenny criteria are met (both paths $a$ and $b$ are significant) but the Sobel test is not (i.e. $a b: \mathrm{Z} \leq 1.96, \mathrm{p}>.05$ ). This contradiction is mainly due to the assumption that the distribution of $a b$ (i.e. $c-c)$ follows a normal distribution, which is questionable especially in small sample size cases (Preacher and Hayes, 2004). However, it is possible to overcome this issue by bootstrapping the sampling distribution of $a b$. This is explained next. 
The idea of bootstrapping is to take a large number of samples of size $n$, where $n$ is the original sample size, from the data, sampling with replacement, and compute the indirect effect $a b$ in each sample (Preacher and Hayes, 2004). In order to determine whether $a b$ is significantly different from zero at the .05 level, the values of both the lower and upper limits (i.e. $L L$ and $U L$ ) of $95 \%$ confidence intervals need to be inspected. The true indirect effect is estimated to lie between the values of these two limits. If the value zero is not in this confidence level (i.e. does not exist between the lower and upper limits values), only then can it be concluded that the indirect effect is indeed significantly different from zero with $95 \%$ confidence. The typical choice of bootstrap samples is 1000, although Hayes (2009) recommends at least 5000.

\section{Results}

\section{Influence of Organisational Variables on MCS Effectiveness}

Hypotheses test results for first level contingency relationships are presented below. Table 5 provides the results for the linear regression $M C S E F C=b_{0 i}+b_{i} X_{i}$ where MCSEFC designates the dependent variable MCS effectiveness and $X_{i}$ represent the contingent factors defined as independent variables in Table 2.

The findings here suggest that organisational variables vary in their influence on MCS effectiveness. Results related to testing hypothesis 1 indicate that centralisation of the companies has a statistically significant influence on the effectiveness of MCS $(\mathrm{F}$ value $=16.87, \beta=.49, \mathrm{p}<.001)$. Therefore, hypothesis 1 is accepted. This is consistent with earlier studies by Bruns and Waterhouse (1975), Merchant (1981), Gul and Chia (1994), Chia (1995), and Chang et al. (2003) that companies with lower levels of centralisation provide managers more flexibility and supported with relevant information to make the appropriate decisions which positively influenced the organisational systems (MAS/MCS) and performance.

Similarly, formalisation is found to have a highly significant influence on the MCS effectiveness $(\mathrm{F}$ value $=82.56, \beta=.78, \mathrm{p}<.001)$, therefore hypothesis 2 is accepted. This is comparable to the findings of previous studies regarding the influence of formalisation on the MCS effectiveness (e.g. Nicolaou, 2000; Fredrickson, 1986; Gerdin, 2005). One possible explanation for the relatively high level of formalisation in the participating Libyan companies operating is the prevalence of the more bureaucratic types of MCS, in particular the formal control type (mean $=3.65$ ) as indicated earlier, implying the dominance of formal procedures in the pursuit of company goals. 
Table 5. Regression Analysis of the Influence of Organisational Variables on MCS Effectiveness (MCSEFC)

\begin{tabular}{|c|c|c|c|c|c|c|c|}
\hline Variables & $R^{2}$ & $\bar{F}$ & $\boldsymbol{b}_{0}$ & $\bar{b}$ & $S E$ & $\operatorname{Beta}(\beta)$ & $t$ \\
\hline Centralisation (CENT) & .24 & 16.87 & 2.99 & .35 & .08 & .49 & $4.10 * * *$ \\
\hline Formalisation (FORM) & .61 & 82.56 & 1.40 & .69 & .07 & .78 & $9.08 * * *$ \\
\hline Environmental uncertainty (ENUC) & .40 & 34.63 & 2.01 & .56 & .09 & .63 & $5.88 * * *$ \\
\hline Competitive strategy (CMSTG) & .40 & 35.41 & 1.67 & .61 & .10 & .63 & $5.95 * * *$ \\
\hline $\begin{array}{l}\text { Manufacturing complexity } \\
\text { (MAPCX) }\end{array}$ & .07 & 3.89 & 3.16 & .25 & .13 & .26 & 1.97 \\
\hline
\end{tabular}

There is also clear support for hypothesis 3 as the results indicate that environmental uncertainty does influence the effectiveness of MCS, echoing the findings of other studies (e.g. Chenhall and Morris, 1986; Baines and Langfield-Smith, 2003; Abdel-Kader and Luther, 2008; Gul and Chia, 1994). For instance, Chenhall and Morris (1986) reported a positive relationship between environmental uncertainty and scope as well as timeliness of MAI, which in turn improved the ability to assess success or failure. In addition, Abdel-Kader and Luther (2008) found that under high uncertainty conditions, companies adopt more sophisticated management accounting practices to achieve tasks effectively.

On the contrary, results related to testing hypothesis 4 indicate that, the level of manufacturing process complexity has no influence on the effectiveness of an MCS ( $\mathrm{F}$ value $=3.89$, not statistically significant), hence hypothesis 4 is rejected. This finding is consistent with those reported by Abdel-Kader and Luther (2008), who found no relationship between production complexity and the level of management accounting practice sophistication. This could imply that the manufacturing process in these Libyan manufacturing companies is relatively static (producing standard products) and its effect on MCS may appear only through particular elements of these systems. In this respect, Baines and Langfield-Smith (2003) reported that changes in manufacturing technology led to changes in MCS/MAI which in turn improved the organisational performance, implying that the influence of manufacturing complexity could appear through MAI.

Results related to testing hypothesis 5 indicate that competitive strategy is found to have a significant influence on MCS effectiveness ( $F$ value $=35.41, p$ $<0.001$ ) and explains $40 \%$ of their variance. Therefore, hypothesis 5 is accepted. This result supports the findings reported by previous studies (e.g. Govindarajan, 1988; Chenhall and Morris, 1995; Kober et al., 2007; Jermias and Gani, 2004; Naranjo-Gil and Hartmann, 2006). For instance, Kober et al. (2007) found a positive relationship between MCS mechanisms and strategic priorities change and suggested that a good match between MCS and strategy influences organisational performance. 
Table 6. Regression Analysis of the Mediating Effect of Management Accounting Information Usefulness

\begin{tabular}{|c|c|c|c|c|c|c|c|c|c|c|c|c|c|}
\hline \multirow[t]{2}{*}{$\begin{array}{l}\text { Independent } \\
\text { Variables }\end{array}$} & \multicolumn{2}{|r|}{ Path $c$} & \multicolumn{2}{|r|}{ - Path a } & \multicolumn{2}{|r|}{ Path b } & \multicolumn{2}{|r|}{ Path ć } & \multicolumn{2}{|c|}{$\begin{array}{c}\text { Sobel test } \\
\text { “ab" }\end{array}$} & \multicolumn{2}{|c|}{$\begin{array}{c}\text { Bootstrapping_ab } \\
\underline{95 \% C I}^{\ddagger}\end{array}$} & \multirow[t]{2}{*}{ Comment } \\
\hline & $B$ & $t$ & $B$ & $t$ & $B$ & $t$ & $\boldsymbol{B}$ & $t$ & $B$ & $z$ & $L L$ & $U \boldsymbol{L}$ & \\
\hline $\begin{array}{l}\text { Centralisation } \\
\text { (CENT) }\end{array}$ & .35 & $4.10 * * *$ & 2.50 & $4.57 * * *$ & .09 & $4.95 * * *$ & .12 & 1.52 & .22 & $3.32 * * *$ & .09 & .42 & FM \\
\hline $\begin{array}{l}\text { Formalisation } \\
\text { (FORM) }\end{array}$ & .69 & $9.08 * * *$ & 3.92 & $6.71 * * *$ & .04 & $2.48 *$ & .52 & $5.28 * * *$ & .16 & $2.31 *$ & .05 & .30 & PM \\
\hline $\begin{array}{l}\text { Environmental } \\
\text { (ENUC) } \\
\text { uncertainty }\end{array}$ & .56 & $5.88 * * *$ & 3.80 & $6.11 * * *$ & .07 & $3.74 * * *$ & .29 & $2.59 *$ & .27 & $3.16^{* *}$ & .11 & .46 & PM \\
\hline $\begin{array}{l}\text { Competitive } \\
\text { (CMSTG) } \\
\text { strategy }\end{array}$ & .61 & $5.95 * * *$ & 4.07 & $6.01 * * *$ & .07 & $3.75 * * *$ & .32 & $2.70 * *$ & .29 & $3.15^{* *}$ & .12 & .53 & PM \\
\hline $\begin{array}{l}\text { Manufacturing } \\
\text { complexity } \\
\text { (MAPCX) }\end{array}$ & .25 & 1.97 & 1.78 & $2.10^{*}$ & .10 & $6.24 * * *$ & .07 & .74 & .18 & $1.97 *$ & .01 & .38 & IE \\
\hline
\end{tabular}

\section{(MAPCX)}

Path $c=$ dependent variable on the independent variable; path $a=$ mediator on the independent variable; path $b=$ dependent variable on the mediator controlling for the independent variable effect; path $\dot{c}=$ dependent variable on the independent variable controlling for the mediator effect.

The $B$ values are the unstandardised regression coefficients.

95\% $C I=95 \%$ confidence interval; $L L=$ lower level; $U L=$ upper level; FM = full mediation; $\mathrm{PM}=$ partial mediation; IE = indirect effect

$* \mathrm{p}<.05 ; * * \mathrm{p}<.01 ; * * * \mathrm{p}<.001$ (two-tailed)

$¥$ Confidence interval is based on 5000 bootstrap samples. 


\section{The Mediating Role of Management Accounting Information}

The preceding section has presented the findings of the initial individual influence of organisational variables on the effectiveness of MCS. This section takes the analysis to a more complex level by introducing the potential effect of a third variable, a mediator, on the first level relationships explained above. Preacher and Hayes (2004) macro, was utilised to examine second level relationships and the results of the mediation regression tests are presented in Table 6 . The results indicate that, excluding manufacturing process complexity, MAI usefulness has a mediating effect on the association between organisational variables and the effectiveness of MCS and therefore subhypotheses H6a-d are accepted. The insignificant initial relationship between manufacturing process complexity and MCS effectiveness means that the mediating role of MAI usefulness cannot be detected in this case and thus subhypothesis H6e is rejected.

Where mediation was observed, the mediating effect differed in nature from one organisational variable to another. So, for centralisation, the simple regression results of MCS effectiveness on this variable indicate a significant total effect (path $c: B=.35, \mathrm{p}<.001$ ), and the indirect effect of centralisation on MCS effectiveness through MAI usefulness is different from zero (Sobel test $a b: \mathrm{Z}=3.32, \mathrm{p}<.001)$ at the $95 \%$ confidence interval based on 5000 bootstrap samples $(L L=.09, U L=.42)$. The paths from centralisation to MAI usefulness (path $a: B=2.50, \mathrm{p}<.001$ ), and MAI usefulness to MCS effectiveness controlling for centralisation effect (path $b: B=.09, \mathrm{p}<.001$ ) also indicate the presence of mediation via MAI. In contrast, the direct effect of centralisation on MCS effectiveness while controlling for MAI usefulness is not significantly different from zero at the $95 \%$ confidence interval (path ć: $B=$ $.12, \mathrm{p}>.05)$. Therefore, it can be stated that the criteria of a full mediation effect are met. In other words, the usefulness of MAI has a full mediation effect on the relationship between centralisation and the effectiveness of MCS which suggests that MCS adopted in these relatively centralised companies tend to be more effective as managers rely more on MAI.

On the other hand, findings relating to the formalisation variable indicate that all four paths $(c, a, b, c)$ are statistically significant at the .05 level. Specifically, the total effect of formalisation on MCS effectiveness is statistically significant (path $c: B=.69, \mathrm{p}<.001$ ) and the indirect effect of formalisation on MCS effectiveness through the usefulness of MAI is not zero (Sobel test $a b: \mathrm{Z}=2.31, \mathrm{p}<.05$ ) at the $95 \%$ confidence interval based on 5000 bootstrap samples $(L L=.05, U L=.30)$. The paths from formalisation to MAI usefulness (path $a$ : $B=3.92, \mathrm{p}<.001$ ), and MAI usefulness to MCS effectiveness while controlling for the effects of formalisation (path $b: B=.04$, $\mathrm{p}<.05)$, as well as the direct effect of formalisation on MCS effectiveness while controlling for the MAI usefulness effect (path $c: B=.52, \mathrm{p}<.001$ ) also indicate the presence of mediation, albeit partial, via MAI. This means that these companies benefit from MAI when rules and control procedures are embedded within organisational routines and systems, therefore in such 
situations this may increase the need for accounting information to monitor companies' actions on an on-going basis.

Hypothesis 6: Management accounting information mediates the effect of first level contingent factors on MCS effectiveness.

\section{Sub-hypotheses}

H6a: MAI has a mediating effect on the relationship between centralisation and the effectiveness of MCS.

$H 6 b$ : MAI has a mediating effect on the relationship between formalisation and the effectiveness of MCS.

H6c: MAI has a mediating effect on the relationship between environmental uncertainty and the effectiveness of MCS.

H6d: MAI has a mediating effect on the relationship between competitive strategy and the effectiveness of MCS.

H6e: MAI has a mediating effect on the relationship between manufacturing process complexity and the effectiveness of MCS.

Results related to the environmental uncertainty variable indicate that the total relationship between this variable and MCS effectiveness is statistically significant at the .05 level (path $c: B=.56, \mathrm{p}<.001$ ). In addition, the indirect effect of environmental uncertainty on MCS effectiveness through the usefulness of MAI (Sobel test $a b: \mathrm{Z}=3.16, \mathrm{p}<.01$ ) is different from zero at the $95 \%$ confidence interval based on 5000 bootstrap samples ( $L L=.11$, $U L=.46$ ). The paths from environmental uncertainty to MAI usefulness (path a: $B=3.80, \mathrm{p}<.001)$, and MAI usefulness to MCS effectiveness while controlling for environmental uncertainty (path $b: B=.07, \mathrm{p}<.001$ ), as well as the direct effect of environmental uncertainty on MCS effectiveness with controlling for MAI usefulness (path $c$ : $B=.29, \mathrm{p}<.05$ ) indicate that the usefulness of MAI as perceived by the respondents partially mediates the effect of environmental uncertainty on the effectiveness of MCS in their companies.

With respect to competitive strategy, the results highlight the total effect of this variable on MCS effectiveness (path $c: B=.61, \mathrm{p}<.001$ ). Likewise, the indirect effect of competitive strategy on MCS effectiveness through MAI usefulness is different from zero (Sobel test $a b: \mathrm{Z}=3.15, \mathrm{p}<.01$ ) at the same level of confidence interval $(L L=.12, U L=.53)$. The paths from competitive strategy to MAI usefulness (path $a: B=4.07, \mathrm{p}<.001$ ) and competitive strategy to MCS effectiveness while controlling for MAI usefulness (path $b: B$ $=.07, \mathrm{p}<.001)$ as well as the direct effect from competitive strategy to MCS effectiveness while controlling of MAI usefulness (path $c: B=.32, \mathrm{p}<.01$ ) indicate the presence of mediation, albeit partial, via MAI.

Finally, given the insignificant initial relationship between manufacturing process complexity and MCS effectiveness (path $c: B=.25, \mathrm{p}>.05$ ), the mediating role of MAI usefulness cannot be detected in this case. Only an 
indirect effect is present. This implies that manufacturing process complexity can only affect MCS effectiveness through the usefulness of MAI.

The significant positive relationship between the level of manufacturing process complexity and MAI usefulness (path $a: B=1.78, \mathrm{p}<.05$ ) implies that managers of large manufacturing companies in Libya emphasise the benefits of MAI as the level of manufacturing process complexity increases. In addition, as MAI usefulness has a significant positive relationship with MCS effectiveness while controlling for manufacturing process complexity (path $b$ : $B=.10, \mathrm{p}<.001$ ), this completes the indirect effect route, as depicted in Figure 2, Panel C.

\section{Discussion}

The results of the first level contingency relationships clearly indicate that, in an emerging economy, such as Libya, the role of organisational characteristics in management control is no less important than what has been reported and extensively discussed in Western-based studies. Similarities with the findings of previous studies exist with regard to the role of formalisation (e.g. Fredrickson, 1986; Nicolaou, 2000; Gerdin, 2005), centralisation (e.g. Bruns and Waterhouse, 1975; Merchant, 1981; Gul and Chia, 1994; Chia, 1995; Chang et al, 2003), environmental uncertainty (e.g. Chenhall and Morris, 1986; Gul and Chia, 1994; Baines and Langfield-Smith, 2003; Abdel-Kader and Luther, 2008), and competitive strategy (e.g. Govindarajan, 1988; Chenhall and Morris, 1995; Kober et al., 2007; Jermias and Gani, 2004; Naranjo-Gil and Hartmann, 2006). The apparent lack of influence of manufacturing process complexity on MCS effectiveness has also been reported elsewhere, for instance in relation to the level of management accounting practice sophistication as in Abdel-Kader and Luther's study (2008) of UK companies.

Moving from first level analysis to examining the role of MAI as an intervening variable in the contingency relationships by applying an advanced statistical tool for small sample data, i.e. the Preacher and Hayes macro, has brought out a set of results that we believe make a positive contribution to the literature and should inform future research effort in this area. Our results show that MAI seems to have a full mediation effect only on the relationship between centralisation and MCS effectiveness. This is due to the presence of significant total as well as indirect effects (paths $c, a, b$ in Table 6). In other words the centralisation variable no longer contributes directly to the prediction of MCS effectiveness once MAI usefulness enters the contingency model (path $\dot{c}$ is not significant). This emphasises the importance, as demonstrated by Chenhall and Morris (1986), of the level of centralisation in relation to management accounting system design which in turn should lead to an effective MCS. Nevertheless, comparison of the overall result presented here to that of other studies is not feasible because what has been reported by previous research (e.g. Mia, 1993; Teerooven and Bhagtaraj, 2008) as mediation is in 
fact simply an indirect relationship between centralisation and MCS that does not involve a mediator variable.

On the other hand, the mediating role of MAI established here with respect to the relationship between formalisation, environmental uncertainty and competitive strategy and MCS effectiveness compares to results reported by a number of previous studies. For example, Nicolaou (2000) found that the degree of formalisation influenced the effectiveness of MAS and this relation was mediated by MAS integration, although the intervening variable model was not explicitly acknowledged in that case as it is in our study. With regard to environmental uncertainty, Mia and Clarke (1999) found that increased market competition was associated with increased use of broad scope of MAI which in turn positively influenced organisational performance. For competitive strategy, Chong and Chong's (1997) study found this to be an important determinant of the use of MAI and a consequent positive influence on business unit performance. Their study effectively covered the mediation role of MAI although this was explicitly analysed and explained in such terms. A similar comparison can also be made with Baines and Langfield-Smith (2003) who showed that a change in emphasis toward a differentiation strategy was accompanied with more reliance on broad scope MAI and this in turn had a positive influence on organisational performance.

The observed partial mediation of MAI with respect to the influence of formalisation, environmental uncertainty and competitive strategy on the effectiveness of MCS requires further clarification. The only difference between the mediation results here and the one for centralisation, is that each of these three variables continues to contribute to the prediction of MCS effectiveness when the mediator is introduced into the contingency model (see paths $c, a, b$, and $c$ in Table 6 for each variable). These findings suggest that other variables, in addition to MAI usefulness, could have a potential mediating effect on these relationships. Finally, the indirect effect of manufacturing process complexity indicates that, as the manufacturing process becomes more complex, the information users in large manufacturing companies in Libya would perceive MAI useful in planning, monitoring, controlling and directing activities, which in turn leads to a better performance of their MCS.

\section{Conclusions and Suggestions for Future Research}

The study has provided a fresh perspective of MCS in large manufacturing companies and a rigorously derived understanding of the role of MAI in facilitating MCS effectiveness from a contingency perspective in an emerging economy. It is worth noting here that accounting information was previously thought not to have much managerial influence in Libya and this was attributed due to a largely ineffectual accounting profession and a corporate sector dictated to by central government (e.g. Mahmud and Russell, 2003; Shareia, 2006, 2014). A significant contribution of this study is in relation to how to identify, measure, and interpret mediated and moderated relationships. There 
are three points to emphasise here. First, there is some confusion in the management accounting literature as to the labelling of a third variable as a moderator or as a mediator. For instance, some authors (e.g. Chong and Chong, 1997; Chong and Eggleton, 2003) wrongly established the consistency or contradiction of their findings with those of other studies, not realising that moderation and mediation results are not directly comparable because they represent totally different relationships. Only one model can represent the true relationship between variables in a particular situation, thus comparing results obtained from different models is questionable. Second, some of the management accounting studies that investigated the mediation relationship (e.g. Mia, 1993; Teerooven and Bhagtaraj, 2008) reported a mediating effect of a third variable, such as MAI usefulness, when in fact their findings only indicated an indirect effect of the independent variable on the dependent variable via that third variable. In other words, those studies neglected the initial (total) effect of the independent variable on the dependent variable and incorrectly proceeded to establish a mediating effect rather than an indirect effect. Third, none of the previous management accounting studies that examined the mediating effect distinguished between full and partial mediation. This distinction is important for properly studying contingency relationships and examples of this can be found in non-accounting literature (e.g. Preacher and Hayes, 2004; Rosopa and Stone-Romero, 2008; MacKinnon and Luecken, 2011). Therefore, the distinction between full and partial mediation effects and the isolation of the indirect effect, as demonstrated in this study, offer a better understanding and provide a deeper interpretation to the intervening relationships which may reduce the criticisms (e.g. Chenhall, 2003) that have been levelled at contingency theory as a viable explanatory framework of complex organisational phenomena.

Given the continuing need to improve understanding of contingent relationships in management control research (Silva-Domingo, 2015), future studies could explore such relationships by positioning MCS at the heart of the effort to overcome the factors that impede effective company participation in value chains. For emerging economies, impediments include informational barriers (e.g. Bloom et al., 2013) and the general lack of managerial capital (Bruhn and Zia, 2013) that is rooted in weak knowledge bases and innovation capabilities (Bamber et al., 2014). To further guide future research efforts, we conclude with suggestions on how to improve on our study's limitations. The first limitation is the reliance on data from large manufacturing companies only, so the findings could not be generalised to SMEs and service sector organisations. Second, future studies would benefit from data triangulation to gain deeper insights into management control practice and managerial sense making in this regard. Third, although the inclusion of the research variables was informed by a thorough review of the literature, future studies of MCS in emerging economies can usefully include specialisation, standardisation and culture (national and organisational) as variables that can potentially influence MCS design and use as well as managers' MAI needs for more effective control. 
Fourth, the extensive but largely inconclusive research effort on management accounting obsolescence and change that started in the 1980s has yet to fully ascertain their effects on MCS, hence an opportunity for more insights into the MAI-MCS relationship, for example by building on the works of Haustein et al. (2014) and Bedford (2015) on MCS and innovation and Gschwantner and Hiebl (2016) on MCS and organisational ambidexterity. Fifth, this study focused exclusively on the effect of MAI usefulness on first level contingency relationships. Thus, it is worth investigating the effect of other potential mediators that may contribute to the association between organisational variables and MCS effectiveness. In addition, the combination of moderating and mediating model variables would be promising for future research. Specifically, it would be fruitful to investigate for which group or at what level the mediation effect, found in this study, works, by examining whether there is moderated mediation. This could be achieved by introducing a moderator variable to the mediating effect, for example by investigating whether the mediating role of MAI depends on the extent to which there has been a positive change in the management accounting systems (e.g. implementation of advanced management accounting practices). Another possibility is to introduce the effect of top management team diversity or level of MAI users' satisfaction to the mediation relationship and examine the moderated mediation. In case mediation is not established, the analysis could then turn to finding what some authors (e.g. Preacher et al., 2007; Muller et al., 2005) call the conditional indirect effect. Also a longitudinal approach could explore the relationship between MCS and competitive strategy as a two-way rather than a unidirectional relationship. Finally, the study used Preacher and Hayes' (2004) macro to capture the mediating effect because of its suitability for small sample size and it is a powerful procedure as it relies on the products of the three tests to reach the final decision. An alternative approach is to use structural equation modelling (SEM), which is appropriate for large samples, to conduct a mediation relationship analysis of MCS dynamics.

\section{References}

Abdel-Kader M, Luther R (2008), The impact of firm characteristics on management accounting practices: a UK-based empirical analysis. The British Accounting Review, 40: 2-27.

Abughalia W, Abusalem A (2013) Libyan foreign trade: a time series analysis. World Review of Business Research, 3: 25-42.

Adebayo A, Annukka J (2009) Strategy, control activities, monitoring and effectiveness. Managerial Auditing Journal, 24: 500-522.

AfDB (2014) Looking for inclusion. The African Development Bank in North Africa annual report. Abidjan, Côte d'Ivoire: African Development Bank (AfDB). 
Albu N, Albu CN (2012) Factors associated with the adoption and use of management accounting techniques in developing countries: the case of Romania. Journal of International Financial Management \& Accounting, 23: 245-276.

Anthony RN, Govindarajan V (2007) Management Control Systems. Chicago: McGraw-Hill Irwin.

Auzair SM (2011) The effect of business strategy and external environment on management control systems: a study of Malaysian hotels. International Journal of Business \& Social Science, 2: 236-244.

Baines A, Langfield-Smith K (2003) Antecedents to management accounting change: A structural equation approach. Accounting, Organizations and Society, 28: 675698.

Bamber P, Fernandez-Stark K, Gereffi G, Guinn A (2014) Connecting Local Producers in Developing Countries to Regional and Global Value Chains: Update. OECD Trade Policy Papers, No. 160, OECD Publishing.

Bampoky B, Meyssonnier F (2012) L'instrumentation du contrôle de gestion dans les entreprises au Senegal. HAL Archives Ouvertes, Id: hal-00690927, France.

Baron RM, Kenny DA (1986) The moderator-mediator variable distinction in social psychological research: conceptual, strategic, and satistical considerations. Journal of Personality and Social Psychology, 51: 1173-1182.

Bedford DS (2015) Management control systems across different modes of innovation: Implications for firm performance. Management Accounting Research, 28: 12-30.

Bloom N, Eifert B, Mahajan A, McKenzie D, Roberts J (2013) Does management matter? Evidence from India. The Quarterly Journal of Economics (2013), 128: $11-51$.

Bruggemann W, Slagmulder R (1995) The impact of technological change on management accounting. Management Accounting Research, 6: 241-252.

Bruhn M, Zia B (2013) Stimulating managerial capital in emerging markets: the impact of business training for young entrepreneurs. Journal of Development Effectiveness, 5: 232-266

Bruns WJ, Waterhouse JH (1975) Budgetary control and organization structure. Journal of Accounting Research, 13: 177-203.

Chang RD, Chang YW, Paper D (2003) The effect of task uncertainty, decentralization and AIS characteristics on the performance of AIS: an empirical case in Taiwan. Information \& Management, 40: 691-703.

Chenhall RH (2007) Theorising contingencies in management control systems research. In: Chapman CS, Hopwood A, Shields MD (eds) Handbook of Management Accounting Research: Volume 1, Oxford: Elsevier, 163-205.

Chenhall RH (2003) Management control systems design within its organizational context: Findings from contingency-based research and directions for the future. Accounting, Organizations and Society, 28: 127-168.

Chenhall RH, Morris D (1986) The impact of structure, environment, and interdependence on the perceived usefulness of management accounting systems. The Accounting Review, 61: 16-35.

Chenhall RH, Langfield-Smith, K (1998) The relationship between strategic priorities, management techniques and management accounting: An empirical investigation using a systems approach. Accounting, Organizations and Society, 23: 243-264.

Chia YM (1995) Decentralization, management accounting system information characteristics and their interaction effects on managerial performance: a Singapore study. Journal of Business Finance and Accounting, 22: 811-830. 
Choe JM (1998) The effects of user participation on the design of accounting information systems. Information \& Management, 34, 185-198.

Chong VK, Chong KM (1997) Strategic choices, environmental uncertainty and SBU performance: a note on the intervening role of management accounting systems. Accounting \& Business Research, 27: 268-276.

Chong VK, Eggleton IRC (2003) The decision-facilitating role of management accounting systems on managerial performance: the influence of locus of control and task uncertainty. Advances in Accounting, 20: 165-197.

Fisher C (1996) The impact of perceived environmental uncertainty and individual differences on management information requirements: a research note. Accounting, Organizations and Society, 21: 361-369.

Fisher J (1995) Contingency-based research on management control systems: categorization by level of complexity. Journal of Accounting Literature, 14: 2448.

Fredrickson JW (1986) The strategic decision process and organizational structure. Academy of Management Review, 11: 280-297.

Gerdin J (2005) Management accounting system design in manufacturing departments: an empirical investigation using a multiple contingencies approach. Accounting, Organizations and Society, 30: 99-126.

Govindarajan V (1988) A contingency approach to strategy implementation at the business-unit level: Integrating administrative mechanisms with strategy. Academy of Management Journal, 31: 828-853.

Govindarajan V (1984) Appropriateness of accounting data in performance evaluation: an empirical examination of environmental uncertainty as an intervening variable. Accounting, Organizations and Society, 9: 125-135.

Govindarajan V, Fisher J (1990) Strategy, control systems, and resource sharing: effects on business-unit performance. Academy of Management Journal, 33, 259285.

Gschwantner S, Hiebl MRW (2016) Management control systems and organizational ambidexterity. Journal of Management Control, 27: 371-404.

Gul FA, Chia YM (1994) The effects of management accounting systems, perceived environmental uncertainty and decentralization on managerial performance: a test of three-way interaction. Accounting, Organizations and Society, 19: 413-426.

Hage J, Aiken M (1969) Routine technology, social structure, and organization goals. Administrative Science Quarterly, 14: 366-377.

Hage J, Aiken M (1967) Relationship of centralization to other structural properties. Administrative Science Quarterly, 12: 72-92.

Hair JF, Celsi MW, Money AH, Samouel P, Page MJ (2016) Essentials of Business Research Methods. New York: Routledge.

Haustein E, Luther R, Schuster P (2014) Management control systems in innovation companies: a literature based framework. Journal of Management Control, 24: 343-382.

Hayes AF (2009) Beyond Baron and Kenny: statistical mediation analysis in the new millennium. Communication Monographs, 76: 408-420.

Hopper T, Tsamenyi M, Uddin S, Wickramasinghe D (2009) Management accounting in less developed countries: what is known and needs knowing. Accounting, Auditing \& Accountability Journal, 22: 469-514.

Hoque Z (2004) A contingency model of the association between strategy, environmental uncertainty and performance measurement: impact on organizational performance. International Business Review, 13, 485-502. 
Hsu LC, Wang CH (2012) Clarifying the effect of intellectual capital on performance: the mediating role of dynamic capability. British Journal of Management, 23: 179-205.

Jermias J, Gani L (2004) Integrating business strategy, organizational configurations and management accounting systems with business unit effectiveness: a fitness landscape approach. Management Accounting Research, 15: 179-200.

King R, Clarkson PM, Wallace S (2010) Budgeting practices and performance in small healthcare businesses. Management Accounting Research, 21: 40-55.

Kober R, Ng J, Paul B (2007) The interrelationship between management control mechanisms and strategy. Management Accounting Research, 18: 425-452.

KPMG (2014) Oil \& Gas in Africa. KPMG Africa Ltd.

Krumwiede KR (1998) The implementation stages of activity-based costing and the impact of contextual and organizational factors. Journal of Management Accounting Research, 10: 239-277.

Langfield-Smith K (2007) A review of quantitative research in management control systems and strategy. In: Chapman CS, Hopwood A, Shields, MD (eds.) Handbook of Management Accounting Research. Volume 2, Oxford: Elsevier, 753-783.

Langfield-Smith K (1997) Management control systems and strategy: a critical review. Accounting, Organizations and Society, 22: 207-232.

MacKinnon DP, Luecken LJ (2011) Statistical analysis for identifying mediating variables in public health dentistry interventions. Journal of Public Health Dentistry, 71: S37-S46.

Mahmud MB, Russell A (2003) An empirical investigation of the development of accounting education and practice in Libya, and of strategies for enhancing accounting education and accounting practice in Libya. Research in Emerging Economies, 5: 197-236.

Merchant KA (1981) The design of the corporate budgeting system: Influences on managerial behavior and performance. The Accounting Review, 56: 813-829.

Mia L (1993) The role of MAS information in organisations: an empirical study. The British Accounting Review, 25: 269-285.

Mia L, Clarke B (1999) Market competition, management accounting systems and business unit performance. Management Accounting Research, 10: 137-158.

Mia L, Winata L (2008) Manufacturing strategy, broad scope MAS information and information and communication technology. The British Accounting Review, 40: 182-192.

Miles RE, Snow CC (1978), Organizational Strategy, Structure and Process. New York \& London: McGraw-Hill.

Muller D, Judd CM, Yzerbyt VY (2005) When moderation is mediated and mediation is moderated. Journal of Personality and Social Psychology, 89: 852-863.

Naranjo-Gil D, Hartmann F (2006) How top management teams use management accounting systems to implement strategy. Journal of Management Accounting Research, 18: 21-53.

Nicita A, Ognivtsev V, Shirotori M (2013) Global supply chains: trade and economic policies for developing countries. Policy Issues in International Trade and Commodities Study Series No. 55, UNCTAD, Geneva.

Nicolaou AI (2003) Manufacturing strategy implementation and cost management systems effectiveness. European Accounting Review, 12: 175-199.

Nicolaou AI (2000) A contingency model of perceived effectiveness in accounting information systems: organizational coordination and control effects. International Journal of Accounting Information Systems, 1: 91-105. 
Porter ME (1980), Competitive strategy: techniques for analyzing industries and competitors. New York \& London: The Free Press,.

Preacher KJ, Hayes AF (2004) SPSS and SAS procedures for estimating indirect effects in simple mediation models. Behavior Research Methods, Instruments \& Computers, 36: 717-731

Preacher KJ, Rucker DD, Hayes AF (2007) Addressing moderated mediation hypotheses: theory, methods, and prescriptions. Multivariate Behavioral Research, 42: 185-227.

Pugh DS, Hickson DJ, Hinings CR, Turner C (1968) Dimensions of organization structure. Administrative Science Quarterly, 13: 65-105.

Rosopa PJ, Stone-Romero EF (2008) Problems with detecting assumed mediation using the hierarchical multiple regression strategy. Human Resource Management Review, 18: 294-310.

Shareia BF (2014) The Libyan accounting profession. International Journal of Social, Education, Economics and Management Engineering, 8: 3583-3591.

Shareia BF (2006) The role of accounting systems in decision making, planning and control in a developing country: the case of Libya. Unpublished Ph.D. thesis, University of Wollongong, New South Wales, Australia

Silva-Domingo 1 (2015) Management control: unsolved problems and research opportunities. Innovar, 25: 11-20.

Sobel ME (1982) Asymptotic confidence intervals for indirect effects in structural equation models. Sociological Methodology, 13: 290-312.

Soobaroyen T, Bhagtaraj P (2008) The effectiveness of management accounting systems: evidence from functional managers in a developing country. Managerial Auditing Journal, 23: 187-219.

Strauß E, Zecher C (2013) Management control systems: a review. Journal of Management Control, 23: 233-268.

Teerooven S, Bhagtaraj P (2008) The effectiveness of management accounting systems: evidence from functional managers in a developing country. Managerial Auditing Journal, 23: 187-219.

Waweru NM, Hoque Z, Uliana E (2004) Management accounting change in South Africa: case studies from retail services. Accounting, Auditing \& Accountability Journal, 17: 675-704. 
